\title{
Acute effects of acetyl-L-carnitine on sodium cyanide- induced behavioral and biochemical deficits
}

Citation for published version (APA):

Prickaerts, J., Blokland, A., Bothmer, J., Honig, W., Markerink - van Ittersum, M., \& Jolles, J. (1998). Acute effects of acetyl-L-carnitine on sodium cyanide-induced behavioral and biochemical deficits.

Neurochemistry International, 33(5), 435-443. https://doi.org/10.1016/S0197-0186(98)00047-3

Document status and date:

Published: 01/01/1998

DOI:

10.1016/S0197-0186(98)00047-3

Document Version:

Publisher's PDF, also known as Version of record

\section{Please check the document version of this publication:}

- A submitted manuscript is the version of the article upon submission and before peer-review. There can be important differences between the submitted version and the official published version of record.

People interested in the research are advised to contact the author for the final version of the publication, or visit the DOI to the publisher's website.

- The final author version and the galley proof are versions of the publication after peer review.

- The final published version features the final layout of the paper including the volume, issue and page numbers.

Link to publication

\footnotetext{
General rights rights.

- You may freely distribute the URL identifying the publication in the public portal. please follow below link for the End User Agreement:

www.umlib.nl/taverne-license

Take down policy

If you believe that this document breaches copyright please contact us at:

repository@maastrichtuniversity.nl

providing details and we will investigate your claim.
}

Copyright and moral rights for the publications made accessible in the public portal are retained by the authors and/or other copyright owners and it is a condition of accessing publications that users recognise and abide by the legal requirements associated with these

- Users may download and print one copy of any publication from the public portal for the purpose of private study or research.

- You may not further distribute the material or use it for any profit-making activity or commercial gain

If the publication is distributed under the terms of Article $25 \mathrm{fa}$ of the Dutch Copyright Act, indicated by the "Taverne" license above, 


\title{
Acute effects of acetyl-L-carnitine on sodium cyanide-induced behavioral and biochemical deficits
}

\author{
Jos Prickaerts ${ }^{\mathrm{a}, *}$, Arjan Blokland ${ }^{\mathrm{b}}$, John Bothmer ${ }^{\mathrm{c}}$, Wiel Honig ${ }^{\mathrm{a}}$, \\ Marjanne Markerink-Van Ittersum ${ }^{\mathrm{a}}$, Jelle Jolles ${ }^{\mathrm{a}}$ \\ a Department of Psychiatry and Neuropsychology, European Graduate School of Neuroscience 'EURON', Maastricht University, P.O. Box 616, \\ 6200, MD Maastricht, The Netherlands \\ ${ }^{\mathrm{b}}$ Department of Psychology, European Graduate School of Neuroscience 'EURON', Maastricht University, P.O. Box 616, 6200 MD Maastricht, \\ The Netherlands \\ ${ }^{\mathrm{c}}$ Janssen Research Foundation, International Clinical R\&D, CNS, B-2340 Beerse, Belgium
}

Received 18 June 1998; received in revised form 4 August 1998; accepted 13 August 1998

\begin{abstract}
In the present study we investigated the effects of acute treatment with acetyl-L-carnitine $(50 \mathrm{mg} / \mathrm{kg}$, i.v. 90 min before the sodium cyanide injection) on a sodium cyanide-induced behavioral deficit in the Morris water escape task. In a first experiment the spatial discrimination performance of the rats was found to be dose-dependently impaired after an i.c.v. injection of sodium cyanide ( 2.5 and $5.0 \mu \mathrm{g}$ ). Acute treatment with acetyl-L-carnitine was found to increase the behavioral deficit after sodium cyanide. these findings were replicated in a second experiment. Based on these results it can be argued that an acute administration of acetyl-L-carnitine appears to potentiate a sodium cyanide-induced behavioral deficit. An additional in vitro experiment with rat brain synaptosomes showed clear effects of administered sodium cyanide on the energy-dependent incorporation of inositol into phosphoinositides and on the ATP concentration. In vitro acetyl-L-carnitine administration had no effect on the sodium cyanide-induced energy depletion. The negative behavioral findings are in contrast with our previously found protective effect of chronic treatment with acetyl-Lcarnitine (via drinking water) on the sodium cyanide-induced behavioral deficit. Since chronic acetyl-L-carnitine treatment has no effect on the phosphoinositide metabolism it was suggested that acetyl-L-carnitine may act via the formation of an ATP-independent reservoir of activated acyl groups. Thus, fatty acids as acylated derivatives can be used for reacylation processes during an acute period of energy depletion. However, we have no clear explanation for the discrepancy in behavioral results between the chronic vs acute treatment of acetyl-L-carnitine at present. Further research is needed to characterize the mechanism of action of acetyl-Lcarnitine in relation to sodium cyanide. (C) 1998 Elsevier Science Ltd. All rights reserved.
\end{abstract}

\section{Introduction}

In animal studies it has been found that chronic treatment with acetyl-L-carnitine (ALCAR) prevented an impaired cognitive performance in aged rats (Barnes et al., 1990; Caprioli et al., 1990; Ghirardi et al., 1988; Ghirardi et al., 1992). In human studies it has been found that the progression of Alzheimer's disease was significantly reduced in patients chronically treated with ALCAR (Pettegrew et al., 1995; Spagnoli et al., 1991). Several possible mechanisms of action of ALCAR in the brain have been hypothesized to explain these neuroprotective effects on cognitive function. Many explanations are based on L-carnitine of which ALCAR is the acetylated form. Both compounds occur naturally in the brain and

\footnotetext{
*Corresponding author. Tel.: +31 43 3881041; Fax: +31 43 3671096; E-mail: jos.prickaerts@np.unimaas.nl
}

play an important role in the transfer of acyl groups across the mitochondrial membrane for subsequent $\beta$ oxidation (Bieber, 1988). However, this role is of minor importance in the brain, since the brain almost exclusively depends on the oxidation of glucose to meet its energy demands.

ALCAR treatment is thought to be more effective than L-carnitine treatment because it is quite possible that the hydrophobic acetyl moiety of ALCAR improves the ability of the drug to cross the blood brain barrier and to be taken up by neuronal tissue (Burlina et al., 1989). ALCAR is regarded as a compound which may attenuate neurodegenerative processes by having a beneficial effect on the energy metabolism, viz via a stimulation of the use of alternative energy sources, such as lipid substrates or ketone bodies (Aureli et al., 1994; Aureli et al., 1990; Benzi et al., 1984; Ohtsuka and Griffith, 1991; Villa and Gorini, 1991; Villa et al., 1986). 
In a previous study we have demonstrated that chronic treatment with ALCAR (via drinking water) had a protective effect on spatial memory performance in the Morris water escape task after acute sodium cyanide $(\mathrm{NaCN})$ intoxication (Blokland et al., 1993). Cyanide is an inhibitor of the electron chain enzyme complex IV and intravenous (i.v.) administration causes a period of 'histotoxic' hypoxia in the brain (MacMillan, 1989). Cyanide does not cause neuronal damage per se (Brierley et al., 1976), and low doses of cyanide are converted within minutes by mitochondrial sulphur transferase into non-toxic sulphur cyanide (Hathway, 1984). We injected $\mathrm{NaCN}$ intracerebroventricularly (i.c.v.) to avoid peripheral systems being affected and found that this treatment impaired spatial memory performance of rats (Blokland et al., 1993). In addition, the hippocampal phosphoinositide metabolism, which is ATP-dependent, was affected, indicating that energy metabolism was indeed impaired after $\mathrm{NaCN}$ administration (Blokland et al., 1993). However, we also found that chronic ALCAR treatment had no effect on the affected hippocampal energy metabolism of $\mathrm{NaCN}$-treated rats as measured by the energy-dependent phosphoinositide metabolism (Blokland et al., 1993). This indicates that ALCAR did not enhance the utilization of alternative energy sources during the acute $\mathrm{NaCN}$-induced energy depletion. Consequently, other explanations have been suggested for the protective effect of chronic ALCAR treatment such as the formation of an ATP-independent reservoir of activated acyl groups (see Blokland et al., 1993).

Based on another study (Rosenthal et al., 1992) we assumed that an acute administration of ALCAR could possibly be even more effective than a chronic ALCAR treatment. Hence, the effects of acute ALCAR administration (i.v.) were evaluated on the spatial memory deficit. In addition, the effects of $\mathrm{NaCN}$ and ALCAR on the energy metabolism were in vitro assessed with rat brain synaptosomes whose energy status was determined by the measurement of energy-dependent inositol incorporation into phosphoinositides and by the measurement of synaptosomal ATP concentrations.

\section{Experimental procedures}

\subsection{Behavioral procedures}

\subsubsection{Animals}

All experimental procedures were approved by the local ethical committee of the Maastricht University for animal experiments and met governmental guidelines. In a first experiment 28 four-month-old male Lewis rats were used. After spatial discrimination learning (see below) the rats were randomly divided into two groups (control, $n=14$; ALCAR, $n=14$ ). In a second experiment 29 threemonth-old male Lewis rats were used which were also randomly divided into two groups after spatial discrimination learning (control, $n=14$, ALCAR, $n=15$ ). All animals were housed individually in standard Makrolon cages on sawdust bedding in an air-conditioned room (about $20^{\circ} \mathrm{C}$ ). They were kept under a 12/12 h light-dark cycle (lights on from 06.00-18.00 h).

\subsubsection{Treatment}

Two weeks before acquisition of the Morris water escape task, the rats were anesthetized with an intraperitoneal (i.p.) injection of pentobarbital $(60 \mathrm{mg} / \mathrm{kg})$ and placed in a stereotaxic frame. Bilateral stainless steel cannulas (outer and inner diameter 0.65 and $0.30 \mathrm{~mm}$, respectively) were implanted above the lateral ventricles. The cannulas were fixed to the skull with acrylic dental cement (Paladur). The coordinates for injection of $\mathrm{NaCN}$ were: -0.8 $\mathrm{mm}$ anterior, $1.55 \mathrm{~mm}$ lateral and $-3.8 \mathrm{~mm}$ from the bregma (Paxinos and Watson, 1986).

After acquisition of the Morris water escape task, the effects of $\mathrm{NaCN}$ injection were evaluated (see below). Ninety min before the $\mathrm{NaCN}$ injection the rats were lightly anesthetized with ether and an injection (volume $1 \mathrm{mg} / \mathrm{kg}$ ) of ALCAR (50 mg/kg or $100 \mathrm{mg} / \mathrm{kg}$ ) or saline $(9 \mathrm{~g} / 1 \mathrm{NaCl}$ ) was given i.v. (penis vena). A pilot study revealed that after $90 \mathrm{~min}$ the ether anesthesia, also together with the ALCAR treatment, had no effect on the spatial (baseline) performance, i.e., this was not different from the asymptotic performance at the end of acquisition. The ALCAR solution was neutralized ( $\mathrm{pH} 7.0)$ with $0.25 \mathrm{M} \mathrm{NaOH}$. In the first experiment, one rat of the control (saline) group died during ether anesthesia. In both experiments a lateral cannula of one rat of the ALCAR group clogged and became useless for $\mathrm{NaCN}$ injections, therefore these rats were excluded from the experiments.

\subsubsection{Spatial discrimination learning}

Two weeks after surgery, the rats were trained on a standard spatial Morris water escape task (Morris, 1981) in a black water tank (diameter $1.22 \mathrm{~m}$ ). The rats were started from four different, randomly chosen, start positions and trained to find an invisible platform (diameter $11 \mathrm{~cm}$ ) at a fixed position in the water tank, $1 \mathrm{~cm}$ below the surface of the water. The water temperature was about $22^{\circ} \mathrm{C}$. A trial lasted until a rat had found the platform or until $60 \mathrm{~s}$ had elapsed. If a rat did not find the platform within $60 \mathrm{~s}$, it was placed on the platform for $3 \mathrm{~s}$ and then removed from the water tank. On the first day, the rats were given four trials. The rats were given eight trials on consecutive days until the rats had attained an asymptotic performance.

\subsubsection{Effects of $\mathrm{NaCN}$ injections}

After the rats had attained an asymptotic performance, the effects of $\mathrm{NaCN}$ injections were evaluated. ALCAR or saline was always injected $90 \mathrm{~min}$ before the $\mathrm{NaCN}$ 
injection. On day one, the rats received four trials (baseline performance), after which they were injected with $\mathrm{NaCN}(2.5 \mu \mathrm{g}$ of salt weight in $2.5 \mu \mathrm{l}$ per injection site). The rats were given four additional trials, 1, 5, 10 and 15 min after the $\mathrm{NaCN}$ injection. The four possible start positions were balanced per group during each post-injection trial. On day three, the rats underwent the same procedure as on day one, but now a dose of $5.0 \mu \mathrm{g} / 2.5$ $\mu l$ per injection site was administered after the baseline measurement. The same procedure was repeated one week later for both doses. In the second experiment a dose of $100 \mathrm{mg} / \mathrm{kg}$ ALCAR (instead of $50 \mathrm{mg} / \mathrm{kg}$ ) was used in an additional third week and on both day one and day three a $\mathrm{NaCN}$ dose of $2.5 \mu \mathrm{g} / 2.5 \mu \mathrm{l}$ per injection site was administered.

\subsection{Biochemical procedures}

\subsubsection{Preparation of synaptosomes}

For the in vitro experiment we also used adult male Lewis rats (see above). After decapitation the head was immediately immersed in liquid nitrogen for $8 \mathrm{~s}$. All subsequent operations were performed at $0-4 \mathrm{C}$. The brain was taken out of the skull rapidly, and the bulbi olfactory, the cerebellum and brainstem were removed. The tissue was homogenized in $0.32 \mathrm{M}$ sucrose, $1 \mathrm{mM}$ EDTA, 10 $\mathrm{mM}$ Tris- $\mathrm{HCl}, \mathrm{pH} \mathrm{7.4,} \mathrm{in} \mathrm{a} \mathrm{total} \mathrm{volume} 10$ times the brain tissue volume by 10 up-and-down strokes of a Potter-Elvehjem Teflon-glass homogenizer (radial clearance $0.125 \mathrm{~mm}, 700 \mathrm{rpm}$ ). The homogenate was spun at 1000 $\mathrm{g}$ for $10 \mathrm{~min}$. After centrifugation of the supernatant at $10,000 \mathrm{~g}$ for $10 \mathrm{~min}$, the resulting crude mitochondrialsynaptosomal pellet was resuspended in homogenization buffer and then applied to a discontinuous Ficoll-sucrose gradient as described by Booth and Clark (Booth and Clark, 1978). The tubes were centrifuged at 100,000 $\mathrm{g}$ for $30 \mathrm{~min}$. Myelin and synaptosomes banded at the first and second interphases, respectively, with the free mitochondria being pelleted at the bottom. The synaptosomal layer was carefully removed and suspended in homogenization buffer. After centrifugation $(11,000 \mathrm{~g}, 15$ $\min , 4^{\circ} \mathrm{C}$ ), the synaptosomal pellet is resuspended in Krebs-Ringer buffer containing $10 \mathrm{mM}$ glucose, $106 \mathrm{mM}$ $\mathrm{NaCl}, 4.7 \mathrm{mM} \mathrm{KCl}, 0.1 \mathrm{mM} \mathrm{CaCl}, 1 \mathrm{mM} \mathrm{Na} \mathrm{HPO}_{4}$, $24.9 \mathrm{mM} \mathrm{NaHCO}, 10 \mathrm{mM}$ Hepes, $1 \mathrm{mM}$ Cytidine, 1.2 $\mathrm{mM} \mathrm{MgCl} 2, \mathrm{pH} 7.4$, saturated with $\mathrm{O}_{2}: \mathrm{CO}_{2}(95: 5 \%)$, in which the synaptosomes were incubated at $37^{\circ} \mathrm{C}$ in a water bath. Protein determination was performed according to the method of Lowry (Lowry et al., 1951).

The number/amount of intact synaptosomes during the incubation was determined by measuring the total lactate dehydrogenase ( $\mathrm{LDH}$, a cytosolically located enzyme) activity in the incubation medium after removing the intact synaptosomes by centrifugation. This total $\mathrm{LDH}$ activity was compared with the total LDH activity in an incubation mixture in which all synaptosomes were broken by sonication. The data from inositol incorporation measurements and ATP concentration measurements were corrected for this leakage of synaptosomes which could be influenced by the different treatments. LDH activity was measured by incubating a sample (30 $\mu \mathrm{g}$ protein) at room temperature with $0.5 \%(\mathrm{v} / \mathrm{v})$ Triton $\mathrm{X}-100,0.5 \mathrm{mM} \mathrm{NADH}, 50 \mathrm{mM}$ Tris- $\mathrm{HCl}, 1 \mathrm{mM}$ EDTA, and $0.25 \mathrm{mM}$ pyruvate, $\mathrm{pH} 7.4$. The rate of disappearance of NADH was measured at $340 \mathrm{~nm}$ against a blank containing no pyruvate. Single determinations for protein, inositol or ATP measurements were always done in triplicate.

\subsection{2. $\left[{ }^{3} \mathrm{H}\right]$-Inositol incorporation}

$\left[{ }^{3} \mathrm{H}\right]$-inositol (Amersham) incorporation into phosphatidylinositol (PI), phosphatidylinositol monophosphate (PIP) and phosphatidylinositol bisphosphate (PIP $)$ in synaptosomes of rat brain was assayed in the Krebs-Ringer buffer as outlined above. $95 \mu 1$ of synaptosomes (approximately $250 \mu \mathrm{g}$ protein) were preincubated for $20 \mathrm{~min}$ in oxygenated buffer at $37^{\circ} \mathrm{C}$ in capped tubes. Thereafter, $5 \mu \mathrm{l}\left[{ }^{3} \mathrm{H}\right]$-inositol $(5 \mu \mathrm{Ci})$ was added, and $10 \mathrm{~min}$ later $25 \mu \mathrm{l}(0.2-20 \mathrm{mM}) \mathrm{NaCN}$ or buffer (control) was added. In case of ALCAR administration, synaptosomes were treated with $0,0.1,1$ or 10 mM ALCAR after $10 \mathrm{~min}$ of preincubation, i.e., $20 \mathrm{~min}$ before the $\mathrm{NaCN}$ treatment. The incubation was terminated by the addition of $2 \mathrm{ml}$ ice-cold chloroform/methanol/13 M HCl (200:100:0.75, by vol.) Carrier lipids were added and a biphasic system was obtained by the addition of $0.375 \mathrm{ml} 0.6 \mathrm{M} \mathrm{HCl}$. The upper phase was removed and the lower phase washed

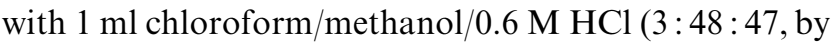
vol.). The resulting lower phase was dried under $\mathrm{N}_{2}$ and redissolved in chloroform/methanol/water $(75: 25: 2$, by vol.). Samples were taken for the determination of radioactivity incorporated into total phospholipids. Phospholipids were separated by high-performance thinlayer chromatography (HPTLC; layer thickness $25 \mu \mathrm{m}$, Merck). Before use, the plates were impregnated with potassium oxalate and activated for $15 \mathrm{~min}$ at $110^{\circ} \mathrm{C}$. The extract was applied to the plate and the lipids were separated with chloroform/acetone/methanol/glacial acetic acid/water (40:15:13:12:8, by vol.). Lipids were visualized with iodine vapor. The spots were scraped from the plate and counted for radioactivity in a liquid scintillation spectrometer.

\subsubsection{ATP concentration measurement}

100 hundred $\mu \mathrm{l}$ synaptosomes (approximately $250 \mu \mathrm{g}$ protein) were preincubated (in Krebs-Ringer buffer) for 15 $\min \left(37^{\circ} \mathrm{C}\right) .25 \mu \mathrm{l}(0.2-20 \mathrm{mM}) \mathrm{NaCN}$ or buffer (control) was added and it was further incubated for another 15 min (or more). In case of ALCAR treatment, $0,0.1,1$ or $10 \mathrm{mM}$ ALCAR was administered just before the start of the preincubation, i.e., $15 \mathrm{~min}$ before the $\mathrm{NaCN}$ treat- 
ment. The incubation was stopped by the addition of icecold concentrated perchloric acid $(33 \mu \mathrm{l})$. After centrifugation $(10,000 \mathrm{~g}, 5 \mathrm{~min})$ the supernatant was neutralized by addition of $95 \mu \mathrm{l} 4 \mathrm{M} \mathrm{KOH} / 1.1 \mathrm{M}$ imidazole $/ 0.8 \mathrm{M} \mathrm{KCl}$. After centrifugation $(10,000 \mathrm{~g}, 5$ min) the supernatant was taken off to measure ATP concentration. Assay conditions for ATP measurement were $100 \mathrm{mM}$ Tris- $\mathrm{HCl}$ (pH 7.4), $1 \mathrm{mM}$ glucose, $5 \mathrm{mM} \mathrm{MgCl}_{2}$, $0.2 \mathrm{mM}$ DTT, $0.03 \mathrm{mM}$ NADP, $0.5 \mu \mathrm{g} / \mathrm{ml}$ yeast glucose6-phosphate dehydrogenase, $1 \mu \mathrm{g} / \mathrm{ml}$ yeast hexokinase, for $30 \mathrm{~min}$ at $37^{\circ} \mathrm{C}$. The reaction was terminated by putting the samples on ice. The appearance of NADPH (which is linearly related to the original amount of ATP) was measured fluorometrically (excitation at $355 \mathrm{~nm}$, emission at $460 \mathrm{~nm}$ ).

\subsection{Statistical analysis}

The mean escape latencies of the pre-injection trials were averaged and taken as baseline performance for each rat. In order to evaluate whether $\mathrm{NaCN}$ treatment affected the performance of the rats, the escape latency during the trials after the animals had received $\mathrm{NaCN}$ was compared with the baseline latency using a paired $t$-test. Treatment effects between groups were evaluated using a $t$-test. For each dose of $\mathrm{NaCN}$, the effects of ALCAR treatment on escape latency 1, 5 and 10 min after the $\mathrm{NaCN}$ injections were also analyzed in a two-factorial (Treatment and Minute) ANOVA with repeated measures over Minute. The biochemical data were analyzed with a Student Newman-Keuls test.

\section{Results}

\subsection{Effects of NaCN and ALCAR injections on spatial discrimination}

\subsubsection{Spatial discrimination performance}

Baseline performance before the $\mathrm{NaCN}$ injection did not differ between the ALCAR-treated rats and the control rats on any occasion in both experiments $(t \mathrm{~s}<1.0$ and 1.3 , respectively, n.s.).

\subsection{2. $\mathrm{NaCN}$ dose $2.5 \mu \mathrm{g}-\mathrm{ALCAR}$ dose $50 \mathrm{mg} / \mathrm{kg}$}

In the first experiment the performance of the control rats did not deviate from baseline performance after injection of $2.5 \mu \mathrm{g} \mathrm{NaCN}$ ( $t \mathrm{~s}<1.6, \mathrm{n} . \mathrm{s}$.). The escape latency of the ALCAR-treated group deviated from its baseline performance during the first trial after injection, i.e, 1 min after $\mathrm{NaCN}$ injection $\left(t_{12}=2.3, P<0.05\right)$. During the second trial after $\mathrm{NaCN}$ injection, i.e., after $5 \mathrm{~min}$, the ALCAR-treated group only showed a tendency to deviate from baseline performance $\left(t_{12}=2.0,0.05<\right.$ $P<0.1)$. Further analysis showed that the escape latencies did decrease during the first three trials after the injection (Minute effect: $F_{2,48}=8.48, P<0.001$; see Fig. $1 \mathrm{~A})$. However, there were no differences in escape latency between the control and ALCAR group during the trials after injection of $\mathrm{NaCN}$ ( $t \mathrm{~s}<0.2$, n.s.; $F \mathrm{~s}<0.5$, n.s.).

In the second experiment, the escape latencies of the control and ALCAR-treated rats deviated from baseline performance during the trials on 1 and 5 min after injection of $2.5 \mu \mathrm{g} \mathrm{NaCN}(t \mathrm{~s}>3.3, P<0.01$; see Fig. 1C). During the first trial after injection the escape latency of the ALCAR-treated tended to be higher than that of the control group $\left(t_{26}=1.99,0.5<P<0.1\right)$. The decrease in escape latency was the same for both experimental groups during the first three trials after the $\mathrm{NaCN}$ injections (Treatment $\times$ Minute effect; $F_{2,52}=1.63$, n.s.).

\subsection{3. $\mathrm{NaCN}$ dose $5.0 \mu \mathrm{g}-\mathrm{ALCAR}$ dose $50 \mathrm{mg} / \mathrm{kg}$}

After $5.0 \mu \mathrm{g} \mathrm{NaCN}$ in the first experiment, the escape latencies of the control and ALCAR-treated rats deviated from baseline performance during the trials on 1 and 5 min after $\mathrm{NaCN}$ injection $(t \mathrm{~s}>4.5, P<0.001$; see Fig. 1B). During the first trial, $1 \mathrm{~min}$ after injection, the increase in escape latency of the ALCAR-treated rats was higher than that of the control rats $\left(t_{24}=-3.47\right.$, $P<0.01)$. In addition, the decrease in escape latency of the ALCAR group during the first three trials after $\mathrm{NaCN}$ injection was higher than that of the control group (Treatment $\times$ Minute effect: $F_{2,48}=5.81, P<0.01$ ).

In the second experiment the escape latencies of the control and ALCAR-treated rats deviated from baseline performance during the trials on 1 and $5 \mathrm{~min}$ after injection of $5.0 \mu \mathrm{g} \mathrm{NaCN}$ ( $t \mathrm{~s}>6.6, P<0.001$; see Fig. 1D). During the second trial, $5 \mathrm{~min}$ after injection, the ALCAR-treated rats tended to have a higher escape latency than control rats $\left(t_{26}=2.0,0.05<P<0.1\right)$. In addition, the return of the escape latency to baseline performance of the ALCAR group after $\mathrm{NaCN}$ injection tended to be slower than that of the control group (Treatment $\times$ Minute effect: $F_{2,52}=2.54,0.05<P<0.1$ ).

\subsection{4. $\mathrm{NaCN}$ dose $2.5 \mu \mathrm{g}-\mathrm{ALCAR}$ dose $100 \mathrm{mg} / \mathrm{kg}$}

In the second experiment a dose of $2.5 \mu \mathrm{g} \mathrm{NaCN}$ appeared already to be sufficient to induce a behavioral deficit (see Fig. 1C). Further, we assumed that after a dose of $5.0 \mu \mathrm{g} \mathrm{NaCN}$, performance could be the result of a ceiling effect (see Fig. 1D). Therefore, it was decided to test additionally a higher dose of ALCAR $(100 \mathrm{mg} / \mathrm{kg})$ in combination with the $\mathrm{NaCN}$ dose of $2.5 \mu \mathrm{g}$ in the rats of the second experiment.

Again it was found that the escape latencies of the control and ALCAR-treated rats deviated from baseline performance during the trials on 1 and 5 min after injection of $2.5 \mu \mathrm{g} \mathrm{NaCN}$ ( $t \mathrm{~s}>3.0, P<0.01$; see Fig. $1 \mathrm{E})$. However, there was no difference in performance between the control rats and ALCAR-treated rats $(t \mathrm{~s}<0.4$, n.s.; $F$ s $<1.1$, n.s.). 


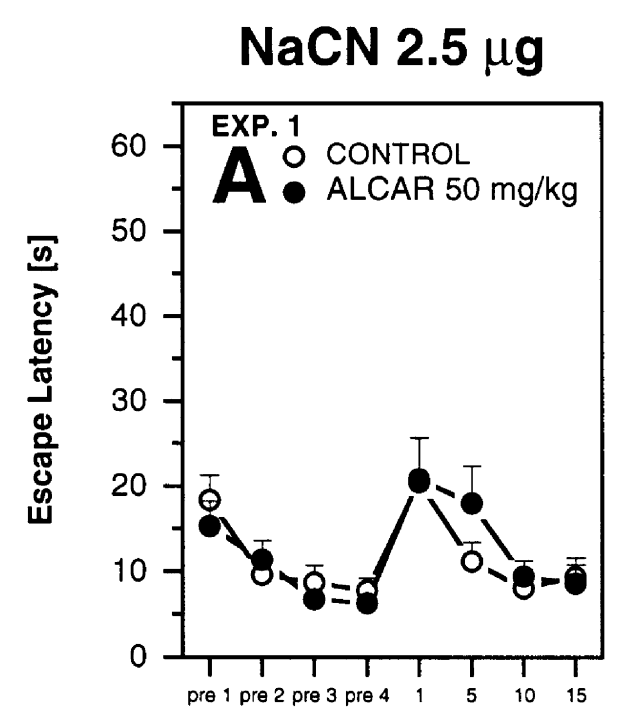

Trials

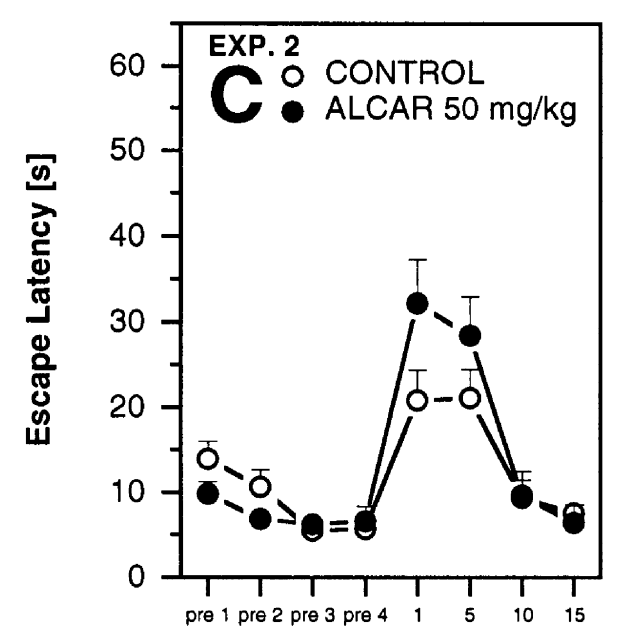

Trials

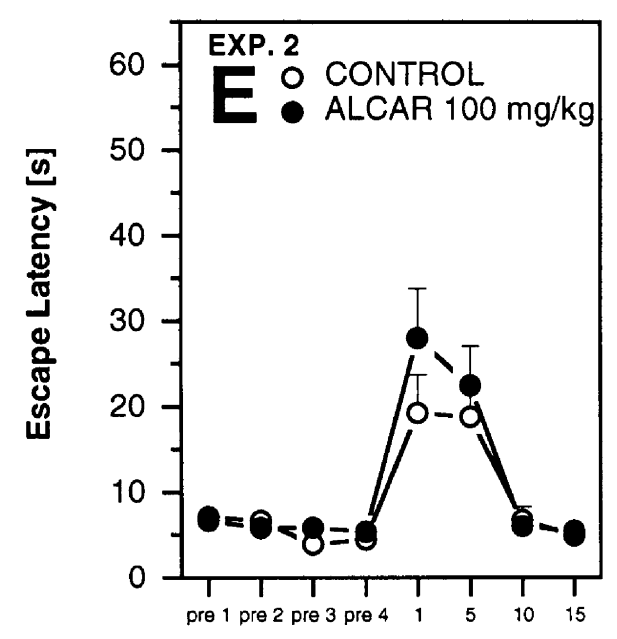

Trials
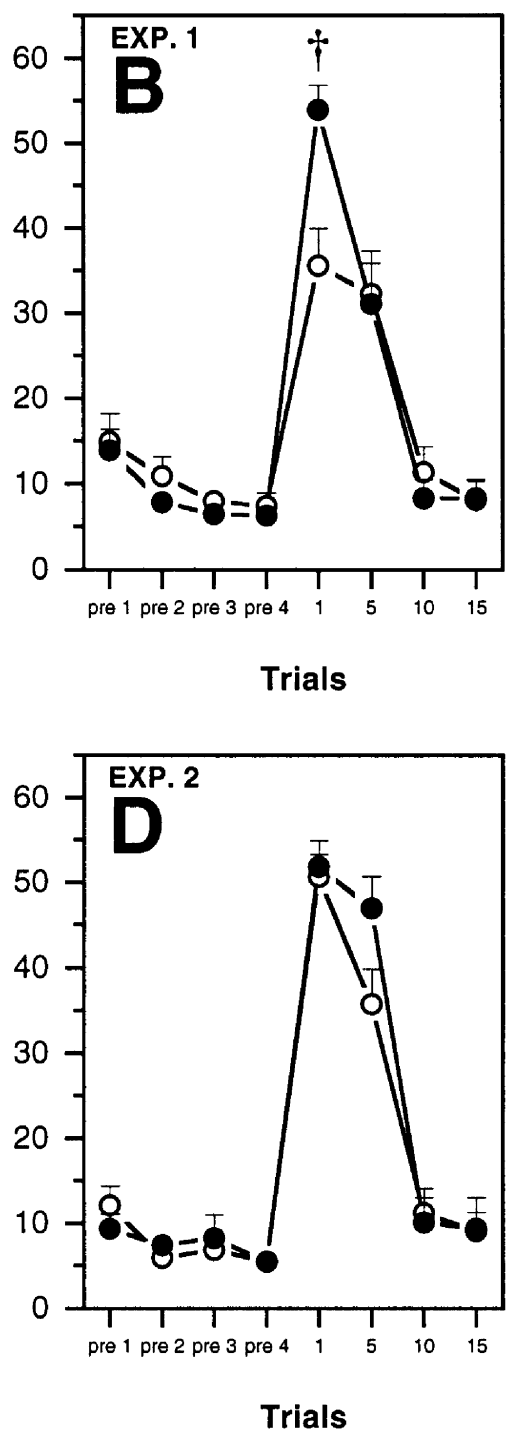

Trials

Fig. 1. Mean escape latency ( + S.E.M.) of control and ALCAR-treated rats during the four pre- and post-injection (NaCN 2.5 or $5.0 \mu$ g, i.c.v.) trials $(1,5,10$ and $15 \mathrm{~min})$ in the Morris water escape task. A dose of $50 \mathrm{mg} / \mathrm{kg}$ ALCAR (i.v.) was tested with $2.5 \mathrm{and} 5.0 \mu \mathrm{g}$ NaCN, respectively, in both the first $(\mathrm{A}, \mathrm{B})$ and second experiment $(\mathrm{C}, \mathrm{D})$. An additional dose of $100 \mathrm{mg} / \mathrm{kg}$ ALCAR (i.v.) was tested with $2.5 \mu \mathrm{g}$ NaCN in the second experiment (E). Treatment effect: $\dagger P<0.01$. 


\subsection{Effects of NaCN and ALCAR on phosphoinositide metabolism and ATP concentrations}

In a pilot study it was found that $\mathrm{NaCN}$ decreased the energy status of rat brain synaptosomes time- and concentration-dependently. A dose of approximately $0.7 \mathrm{mM}$ $\mathrm{NaCN}$ had $50 \%$ of the maximal effect on $\left[{ }^{3} \mathrm{H}\right]$-inositol incorporation into PI, PIP and $\mathrm{PIP}_{2}$ for an incubation period of $60 \mathrm{~min}$. For $50 \%$ of the maximal effect on the ATP concentration, the dose of $\mathrm{NaCN}$ was approximately $0.3 \mathrm{mM}$ for an incubation period of $15 \mathrm{~min}$. With these results, an in vitro energy-deficiency model was established; $0.7 \mathrm{mM} \mathrm{NaCN}$ addition to rat brain synaptosomes for a $15 \mathrm{~min}$ incubation period (ATP measurements) or $60 \mathrm{~min}$ incubation period (inositol incorporation assay), which was used to evaluate properties of ALCAR. However, it is noteworthy to mention that since the inositol incorporation showed no recovery after $60 \mathrm{~min}$ of $\mathrm{NaCN}$ incubation, which was also observed for the measured ATP concentrations, it appears that the synaptosomes could not recover from the $\mathrm{NaCN}$-induced energy depletion.

The incorporation of $\left[{ }^{3} \mathrm{H}\right]$-inositol into ALCARtreated $(0,0.1,1.0$ or $10 \mathrm{mM})$ synaptosomes was measured and compared with a sample of untreated synaptosomes, i.e., no ALCAR and no $\mathrm{NaCN}$ treatment. Figure 2 shows a clear effect of $\mathrm{NaCN}$ on the incorporation of $\left[{ }^{3} \mathrm{H}\right]$-inositol into PI, PIP and $\mathrm{PIP}_{2}$, as expected. However, the in vitro ALCAR-treated synaptosomes were not different from the $\mathrm{NaCN}$-treated synaptosomes incubated without ALCAR, indicating that ALCAR administered in vitro has no effect on the lowered energy status of synaptosomes.

The ATP concentration of ALCAR-treated $(0,0.1,1.0$ or $10 \mathrm{mM}$ ) synaptosomes was measured and also compared with a sample of untreated synaptosomes. Figure 3 shows a clear effect of $\mathrm{NaCN}$ on the concentration of ATP in synaptosomes, as expected. The in vitro ALCARtreated synaptosomes, however, did not differ from the $\mathrm{NaCN}$-treated synaptosomes incubated without ALCAR. This indicates again that ALCAR administered in vitro has no effect on the lowered energy status of synaptosomes.

\section{Discussion}

After a dose of $2.5 \mu \mathrm{g} \mathrm{NaCN}$ the spatial memory performance of the rats in the first experiment was not consistently affected. However, the data did suggest that at this dose of $\mathrm{NaCN}$, spatial discrimination behavior in the ALCAR-treated rats is yet somewhat affected. A dose of $5.0 \mu \mathrm{g} \mathrm{NaCN}$ was sufficient to disrupt the performance of the rats 1 and $5 \mathrm{~min}$ after injection. Acute treatment with ALCAR was found to increase the behavioral deficit after this dose of $\mathrm{NaCN}$.

The composition of neuronal membranes undergo ageassociated changes (Schoeder, 1984) and concomitantly it has been found that in aged rat brain there is a decrease in activity of the enzyme lysophospholipid acyltransferase which is necessary for the reacylation of plasma membrane phospholipids out of lysophos-

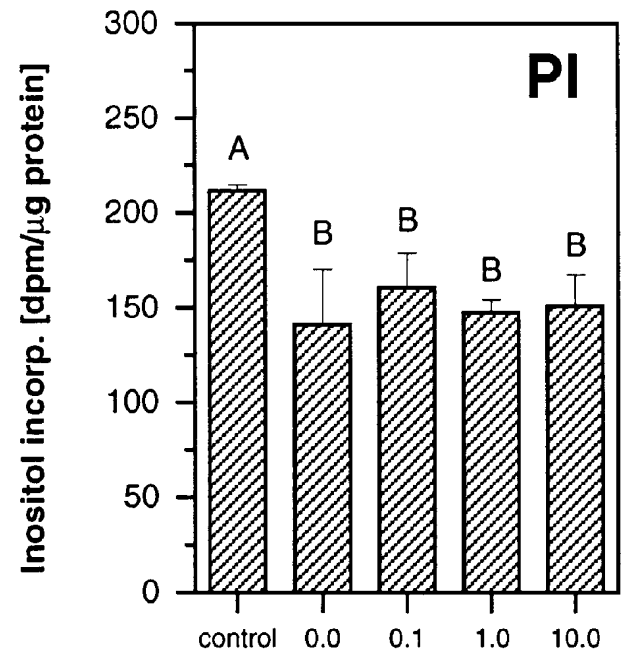

ALCAR conc. [mM]

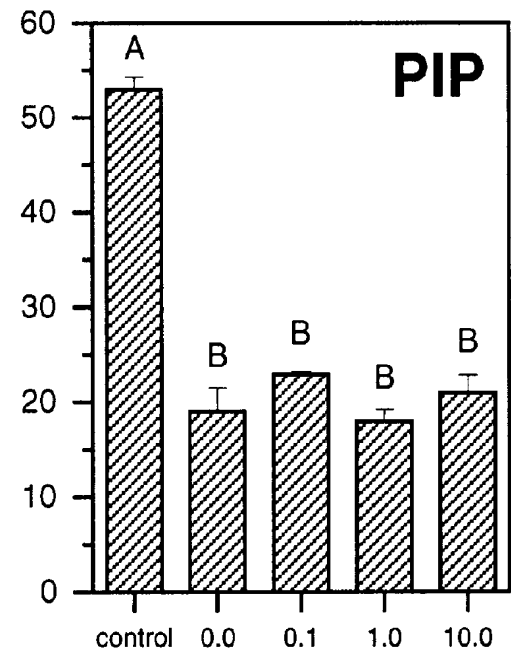

ALCAR conc. [mM]

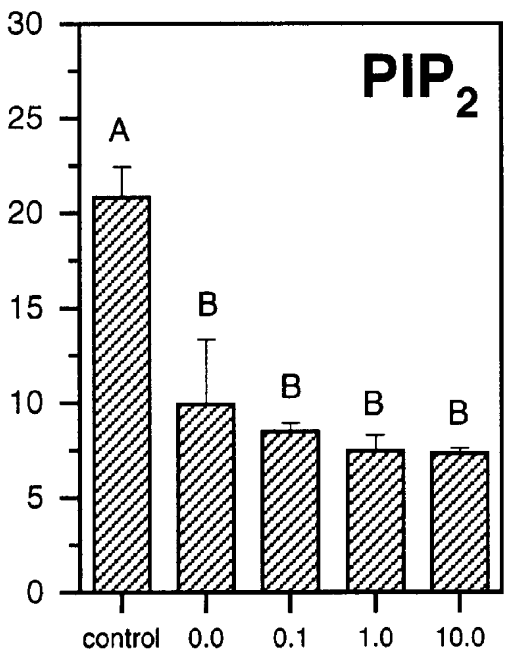

ALCAR conc. [mM]

Fig. 2. The effect of ALCAR administered in vitro $(0,0.1,1$ and $10 \mathrm{mM})$ on the $\mathrm{NaCN}-(0.7 \mathrm{mM})$-induced inhibition of the incorporation of [3H]inositol (5 $\mu \mathrm{Ci}$ /incubation) into phosphatidylinositol (PI), phosphatidylinositol monophosphate (PIP) and phosphatidylinositol bisphosphate (PIP ${ }_{2}$ ) of synaptosomes (approximately $250 \mu \mathrm{g}$ protein/incubation) prepared from rat forebrain, during a 60 min incubation at $37^{\circ} \mathrm{C}$ after $30 \mathrm{~min}$ preincubation without $\mathrm{NaCN}$. ALCAR was administered after $10 \mathrm{~min}$ of preincubation. Control is untreated synaptosomes, i.e., no ALCAR and no $\mathrm{NaCN}$ treatment. Each value is the mean $(+$ S.E.M.) of three determinations. Values which were different (Student Newman-Keuls test: $P<0.05$ ) were marked with different characters. 


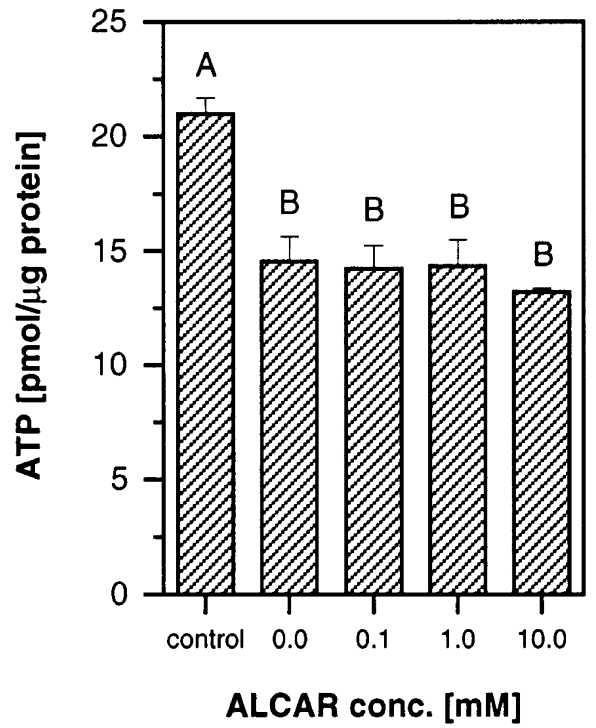

Fig. 3. The effect of ALCAR administered in vitro $(0,0.1,1$ and $10 \mathrm{mM})$ on the $\mathrm{NaCN}-(0.7 \mathrm{mM})$-induced decrease of the ATP concentration of synaptosomes (approximately $250 \mu \mathrm{g}$ protein/incubation) prepared from rat forebrain, during a $15 \mathrm{~min}$ incubation at $37^{\circ} \mathrm{C}$ after $15 \mathrm{~min}$ preincubation without $\mathrm{NaCN}$. ALCAR was administered just before the start of the preincubation. Control is untreated synaptosomes, i.e., no ALCAR and no $\mathrm{NaCN}$ treatment. Each value is the mean $(+$ S.E.M.) of three determinations. Values which were different (Student Newman-Keuls test; $P<0.05)$ were marked with different characters.

pholipids and acyl-CoAs (Aureli et al., 1990; Miccheli et al., 1988). These acyl-CoAs are produced out of free fatty acids (originating from deacylation of membrane phospholipids) by the enzyme acyl-CoA synthetase which requires energy (ATP). Arduini et al. (1994) proposed a working mechanism for L-carnitine which suggests that L-carnitine is involved in brain phospholipid metabolism via the enzyme carnitine acyltransferase (probably a plasma membrane associated palmitoyltransferase). According to Arduini's mechanism, L-carnitine provides an ATP-independent reservoir of acyl groups for reacylation, by shifting the equilibrium for carnitine acyltransferase toward acyl-L-carnitines. This could be of main importance when the ATP-dependent reacylation route via acyl-CoA synthetase is inhibited by a low energy metabolism in the brain, like during hypoxia or ischemia (see below). In addition, this might also explain the observed increase in acyl-L-carnitines during aging (Maccari et al., 1990), i.e., a removal of a possible excess of acyl-CoAs, which might arise because reacylation is reduced (Aureli et al., 1990; Miccheli et al., 1988), takes place.

The above mentioned mechanism is probably not per se of importance in normal healthy adult rats, unless membranes have been damaged due to for instance hypoxia, ischemia or hypoglycemia and thus reacylation/deacylation processes become involved. When energy metabolism is impaired due to ischemia (Ikeda et al., 1986), hypoxia or hypoglycemia (Ando et al., 1993), there is an increase in deacylation of membrane phospholipids and a decrease in $\beta$-oxidation. This results in an increase in free fatty acids and acyl-CoAs, respectively, of which the latter are toxic for the mitochondrion both via an inhibition of the electron chain enzyme complexes (Ohtsuka and Griffith, 1991) and via mitochondrial membrane damage (Pastorino et al., 1993), and thus can contribute to an impaired neuronal function or even lead to neuronal damage. It seems likely that ALCAR via Lcarnitine diminishes the accumulation of toxic acyl-CoAs by shifting the equilibrium for carnitine acyltransferase towards acyl-L-carnitines (cf Ohtsuka and Griffith, 1991). However, this may be of minor relevance in the brain because of the low carnitine acyltransferase activity in the brain due to its preference for glucose. But a detoxification function (and also the formation of a ATPindependent acyl reservoir) may still play a role, since it appears that next to an increase in acyl-CoAs, there is an increase in acyl-L-carnitines in the brain during ischemia (see Bohan, 1992). Taken together, it is likely that an increase in ALCAR and/or L-carnitine levels prevents, by formation of acyl-L-carnitines, a too high level of acyl-CoAs both inside and outside the mitochondrion. A mitochondrion membrane associated carnitine acyltransferase may be responsible for this inside the mitochondrion, while at its outside a mitochondrion and/or plasma membrane associated enzyme may be involved (cf Arduini et al., 1994).

The increased $\mathrm{NaCN}$-induced behavioral deficit by acute ALCAR treatment might be explained by an inhibition of the glycolytic flow, because it has been found that ALCAR is not only involved in brain energy metabolism by stimulating the use of alternative energy sources, but also by inhibiting the glycolytic flow (Aureli et al., 1994; Aureli et al., 1990; Benzi et al., 1984; Villa and Gorini, 1991; Villa et al., 1986). Consequently, acute ALCAR treatment would further increase the energy deficit due to $\mathrm{NaCN}$. With respect to a possible inhibition of the glycolysis it has been found in an aging study that acute administration of ALCAR (75 mg/kg, i.p.) inhibited the glycolytic flow in the brain, next to the increased use of alternative energy sources, of both young and old rats (Aureli et al., 1990). In addition, an indication was found that this dose of ALCAR had an effect on reacylation/deacylation processes. However, this only applied to young rats. Only a very high dose of ALCAR $(500 \mathrm{mg} / \mathrm{kg})$ appeared to have an effect on the reacylation/deacylation processes in the brain of old rats, while at the same time the glycolytic inhibition stayed the same as with the low dose. Hence, one may assume that a higher dose of acutely administered ALCAR might be protective against $\mathrm{NaCN}$, since its ATP-independent acyl reservoir (or detoxification) function may then overcome its inhibition of the glycolytic flow. Therefore, the experi- 
ment was replicated and additionally a higher dose of ALCAR was tested.

In the second experiment, a dose of $2.5 \mu \mathrm{g} \mathrm{NaCN}$ was already sufficient to produce a spatial memory deficit in all the rats. In addition, the spatial memory performance of the ALCAR-treated (same dose as in first experiment) rats tended to be even more affected than that of the control rats after both 2.5 and $5.0 \mu \mathrm{g} \mathrm{NaCN}$ administration. This finding is in agreement with the first experiment with acute ALCAR and $\mathrm{NaCN}$. Therefore, it can be argued that an acute (i.v.) administration of ALCAR potentiates a $\mathrm{NaCN}$-induced behavioral deficit.

In contrast to acute administration, we have found that chronic treatment with ALCAR (via drinking water) attenuated the $\mathrm{NaCN}$-induced behavioral deficit, although it had no effect on the energy-dependent phosphoinositide metabolism as was measured by the incorporation of inositol into PIP and $\mathrm{PIP}_{2}$ in a hippocampal lysed $\mathrm{P}_{2}$ fraction (Blokland et al., 1993). Additionally, we have found that in synaptosomes of chronically ALCARtreated rats, the ALCAR treatment had no effect on the energy-dependent inositol incorporation into PI, PIP and $\mathrm{PIP}_{2}$, and ATP concentrations after NaCN administration (unpublished data). Based on these findings the protective effect of chronic treatment with ALCAR against $\mathrm{NaCN}$ administration might be explained with the formation of the ATP-independent reservoir of activated acyl groups. Thus fatty acids as acylated derivatives are available and reacylation processes can continue during acute $\mathrm{NaCN}$ intoxication (cf Arduini et al., 1994). On the other hand, or maybe concomitantly, ALCAR may exert its protective action by preventing a possible accumulation of toxic acyl-CoAs (cf Ohtsuka and Griffith, 1991).

As already discussed above, the potentiation of the $\mathrm{NaCN}$-induced behavioral deficit by acute administration of ALCAR might be explained by an inhibition of the glycolytic flow. Effects of ALCAR, after acute administration, on the possible formation of an activated acyl-L-carnitines reservoir may be too small or short lasting in order to have a protective effect. However, when increasing the dose of ALCAR, which was tested with the smallest behavioral deficit, i.e., after $2.5 \mu \mathrm{g} \mathrm{NaCN}$, the lack of a behavioral difference between the ALCAR and control rats after $\mathrm{NaCN}$ administration suggest that a possible inhibition of the glycolytic flow might be overcome (compare Fig. 1E with 1C).

Except for the assumed inhibition of the glycolytic flow, we have no clear explanation for the potentiating effect of acutely administered ALCAR on a NaCNinduced behavioral deficit. However, our in vitro data are not in complete agreement with the behavioral data since no potentiating effect was observed. But at least the lack of a protective effect of acute ALCAR treatment against $\mathrm{NaCN}$ is in agreement with our in vitro findings in synaptosomes that acutely administered ALCAR had no protective effect on the energy-dependent inositol incorporation into phosphoinositides and ATP concentrations after $\mathrm{NaCN}$ administration. In addition, these data are corroborated by another study which showed that acute L-carnitine administration did not prevent cyanide-induced death of cultured cells (Pastorino et al., 1993). The explanation for the latter was that, although the toxic Acyl-CoAs were scavenged by L-carnitine, the increased phospholipase activity due to the energy deficiency was already sufficient, or such to cause enough membrane damage to result in cell death.

It has been found that the time of administration of a protective drug is best immediately after an ischemic insult, since otherwise the possibility exists that the drug treatment has no effects or even potentiates detrimental effects of the insult (e.g., Borlongan et al., 1995). Therefore, administration of ALCAR after the $\mathrm{NaCN}$ injection might have had resulted in a protective effect. However, $\mathrm{NaCN}$ causes hypoxia and it has been found with respect to hypoxia the time of administration of a protective drug, i.e., before or after the insult, is not so important (e.g., Speiser et al., 1991). Moreover, chronic ALCAR treatment that started long before the insult, did have a protective effect against $\mathrm{NaCN}$ treatment. Perhaps it is more useful to administer ALCAR or L-carnitine centrally. Especially L-carnitine is interesting because it may have less or no inhibiting effect on the glycolytic flow as ALCAR has. Thus, the effective component in the brain can be assessed, viz ALCAR or L-carnitine, or perhaps, both. Concomitantly, with respect to the ATPindependent reservoir of activated acyl groups, ALCAR has to be first converted to L-carnitine, in order to shift the equilibrium of the enzyme carnitine acyltransferase towards acyl-L-carnitines. Therefore, additional (mainly biochemical (cf Arduini et al., 1994)) research is needed to investigate this possible action of ALCAR after chronic administration in relation to $\mathrm{NaCN}$.

In conclusion, chronic administration (via drinking water) of ALCAR may probably have exerted its positive action on the $\mathrm{NaCN}$-induced spatial memory deficit via the formation of an energy-independent acylcarnitines reservoir and/or detoxification of toxic acyl-CoAs. However, acute administration (i.v.) of ALCAR appeared to potentiate the $\mathrm{NaCN}$-induced cognitive deficit, for which no adequate explanation exists at present. These findings indicate that the nootropic effect of ALCAR has more to do with neuroprotection than with cognition enhancement. Therefore, it is best to administer ALCAR chronically, and preferably as early as possible, to prevent/attenuate cognitive dysfunction such as occurs in for instance Alzheimer's disease.

\section{Acknowledgement}

We thank Sigma-Tau Company (Pomezia-Rome, Italy) for the financial support and for providing us with acetylL-carnitine. 


\section{References}

Ando, S., Waki, H., Kon, K., 1993. Differential fatty acid release from CA1 and CA3 regions of rat hippocampal slices under hypoxia and hypoglycemia. Neurosci. Lett. 151, 48-50.

Arduini, A., Denisova, N., Virmani, A., Avrova, N., Federici, G., Arrigoni-Martelli, E., 1994. Evidence for the involvement of carnitine-dependent long-chain acyltransferases in neuronal triglyceride and phospholipid acid turnover. J. Neurochem. 62, 15301538.

Aureli, T., Miccheli, A., Di Cocco, M.E.L., Ghirardi, O., Giuliani, A., Ramacci, M.T., Conti, F., 1994. Effect of acetyl-L-carnitine on recovery of brain phosphorus metabolites and lactic acid level during reperfusion after cerebral ischemia in the rat-study by $31 \mathrm{P}$ and 1H-NMR spectroscopy. Brain Res. 643, 92-99.

Aureli, T., Miccheli, A., Ricciolini, R., Di Cocco, M.-A., Ramacci, M.T., Angelucci, L., Ghirardi, O., Conti, F., 1990. Aging brain: Effect of acetyl-L-carnitine treatment on rat brain energy and phospholipid metabolism. A study by $31 \mathrm{P}$ and $1 \mathrm{H}$ NMR spectroscopy. Brain Res. 526, 108-112.

Barnes, C.A., Markowska, A.L., Ingram, D.K., Kametani, H., Spangler, E.L., Lemken, V.J., Olton, D.S., 1990. Acetyl-L-carnitine 2: Effects on learning and memory performance of aged rats in simple and complex mazes. Neurobiol. Aging 11, 499-506.

Benzi, G., Villa, R.F., Dossena, M., Vercesi, L., Gorini, A., Pastoris, O., 1984. Cerebral endogenous substrate utilization during the recovery period after profound hypoglycemia. J. Neurosci. Res. 11, 437-450.

Bieber, L.L., 1988. Carnitine. Ann. Rev. Biochem. 57, 261-283.

Blokland, A., Bothmer, J., Honig, W., Jolles, J., 1993. Behavioral and biochemical effects of acute central metabolic inhibition: Effects of acetyl-L-carnitine. Eur. J. Pharmacol. 235, 275-281.

Bohan, T.P., 1992. Editorial comment. Stroke 23, 1317-1318.

Booth, R.F.G., Clark, J.B., 1978. A rapid method for the preparation of relatively pure metabolically competent synaptosomes. Biochem. J. 176, 365-370.

Borlongan, C.V., Cahill, D.W., Sanberg, P.R., 1995. Locomotor and passive avoidance deficits following occlusion of the middle cerebral artery. Physiol. Behav. 58, 909-917.

Brierly, J.B., Brown, A.W., Calverley, J., 1976. Cyanide intoxication in the rat: Physiological and neuropathological aspects. J. Neurol. Neurosurg. Psychiatry 39, 129-140.

Burlina, A.P., Sershen, H., Debler, E.A., Lajtha, A., 1989. Uptake of acetyl-L-carnitine in the brain. Neurochem. Res. 14, 489-493.

Caprioli, A., Ghirardi, O., Ramacci, M.T., Angelucci, L., 1990. Agedependent deficits in radial maze performance in the rat: Effect of chronic treatment with acetyl-L-carnitine. Prog. Neuropsychopharmacol. Biol. Psychiat. 14, 359-369.

Ghirardi, O., Caprioli, A., Milano, S., Giuliani, A., Ramacci, M.T., Angelucci, L., 1992. Active Avoidance Learning in old rats chronically treated with levocarnitine acetyl. Physiol. Behav. 52, 185-187.

Ghirardi, O., Milano, S., Ramacci, M.T., Angelucci, L., 1988. Effect of acetyl-L-carnitine chronic treatment on discrimination models in aged rats. Physiol. Behav. 44, 769-773.

Hathway, D.E., 1984. Molecular aspects of toxicology. The Royal Society of Chemistry, London, pp. 84.
Ikeda, M., Yoshida, S., Busto, R., Santiso, M., Ginsberg, M.D., 1986. Polyphosphoinositides as a probable source of brain free fatty acids accumulated at the inset of ischemia. J. Neurochem. 47, 123-132.

Lowry, O.L., Rosebrough, N.J., Farr, A.L., Randall, R.J., 1951. Protein measurements with the Folin Phenol reagent. J. Biol. Chem. 193, 265-275.

Maccari, F., Arseni, A., Chiodi, P., Ramacci, T., Angelucci, L., 1990. Levels of carnitines in brain and other tissues of rats of different ages. Effect of acetyl-L-carnitine administration. Exp. Gerontol. 25, 127-134.

MacMillan, V.H., 1989. Cerebral energy metabolism in cyanide encephalopathy. J. Cereb. Blood Flow Metab. 9, 156-162.

Miccheli, A., Delfini, M., Aureli, T., Di Cocco, M.E., Tomasini, A., Calderini, G., Conti, F., 1988. Aging brain: H-1 and P-31 NMR spectroscopy study energy and phospholipid metabolism. Magn. Res. Med. Biol. 1, 157-168.

Morris, R.G.M., 1981. Spatial localization does not require the presence of local cues. Learn. Motiv. 12, 239-261.

Ohtsuka, Y., Griffith, O.W., 1991. L-carnitine protection in ammonia intoxication. Biochem. Pharmacol. 12, 1957-1961.

Pastorino, J.G., Snyder, J.W., Serroni, A., Hoek, J.B., Farber, J.L., 1993. Cyclosporin and carnitine prevent the anoxic death of cultured hepatocytes by inhibiting the mitochondrial permeability transition. J. Biol. Biochem. 268, 13791-13798.

Paxinos, G., Watson, C., 1986. The rat brain in stereotaxic coordinates, 2nd ed. Academic Press, San Diego.

Pettegrew, J.W., Klunk, W.E., Panchalingam, K., Kanfer, J.N., McClure, R.J., 1995. Clinical and neurochemical effects of acetylL-carnitine in Alzheimer's disease. Neurobiol. Aging 16, 1-4.

Rosenthal, R.E., Williams, R., Bogaert, Y.E., Getson, P.R., Fiskum, G., 1992. Prevention of post-ischemic neurologic injury through potentiation of brain energy metabolism by acetyl-L-carnitine. Stroke 23, 1312-1317.

Schoeder, F., 1984. Role of membrane lipid asymmetry in aging. Neurobiol. Aging 5, 323-333.

Spagnoli, A., Lucca, U., Menasce, G., Bandera, L., Cizza, G., Forloni, G., Tettamanti, M., Frattura, L., Tiraboschi, P., Comelli, M., Senin, U., Longo, A., Petrini, A., Brambilla, G., Belloni, A., Negri, C., Cavazzuti, F., Salsi, A., Calogero, P., Parma, E., Stramba-Badiale, M., Vitali, S, Andreoni, G., Inzoli, M.R., Santus, G., Caregnato, R., Peruzza, M., Favaretto, M., Bozeglav, C., Alberoni, M., De Leo, D., Serraiotto, L., Baiocchi, A., Scoccia, S., Culotta, P., Ieracitano, D., 1991. Long-term acetyl-L-carnitine treatment in Alzheimer's disease. Neurology 41, 1726-1732.

Speiser, Z., Uziel, J., Defirin-Assa, R., Gitter, S., Urca, G., 1991. Different behavioral deficits are induced by anoxia/hypoxia in neonatal and senescent rats: Blockade by MK-801. Brain Res. 42, 181186.

Villa, R.F., Gorini, A., 1991. Action of L-acetylcarnitine on different cerebral mitochondrial populations from hippocampus and striatum during aging. Neurochem. Res. 16, 1125-1132.

Villa, R.F., Gorini, A., Zanada, F., Benzi, G., 1986. Action of Lacetylcarnitine on different cerebral mitochondrial populations from hippocampus. Arch. Int. Pharmacodyn. 279, 195-211. 